\title{
Eimeria Spp.Infection in Some Broiler Farms in Khartoum State, Sudan
}

\author{
Awad Abdelrahman Alzib ${ }^{1}$, Ghada Hassan Abdelnabi ${ }^{{ }^{*}}$ \\ ${ }^{1}$ Department of Parasitology, Faculty of Veterinary Medicine, University of Khartoum, Khartoum North, Sudan
}

Received: 09 June, 2017; Accepted: 22 August, 2017; Published: 13 September, 2017

*Corresponding author: Ghada Hassan Abdelnabi, Department of Parasitology, Faculty of Veterinary Medicine, University of Khartoum, Khartoum North, Sudan; E mail: ghadabdelnabi@hotmail.com.

\begin{abstract}
A cross sectional study was conducted during October 2013 to February 2014 to identify and determine the prevalence of Eimeria spp. among broiler chickens reared in open and closed systems in Khartoum, Khartoum North, and Omdurman, Khartoum State, Sudan. A total of 90 broiler intestines were collected from slaughtered broilers at slaughterhouse or farms and examined by direct smear and standard floatation test to detect Eimeria species. The overall prevalence of Eimeria spp. was $5.5 \%$ of the examined samples. Two Eimeria species were identified viz, Eimeria tenella and Eimeria acervulina. E. tenella was the dominant species with an infection rate of $5.5 \%$ followed by E. acervulina $2.2 \%$. The prevalence of Eimeria spp. in open and closed systems was $4.4 \%$ and $6.7 \%$, respectively. The overall prevalence of Eimeria spp. was $10 \%, 6.7 \%$ and $0 \%$ in Khartoum, Khartoum North and Omdurman, respectively. No significant associations $(\mathrm{P}>0.05)$ were observed between different locations and management systems employed of the examined chickens. Further epidemiological studies should be conducted to determine the prevalence and identify Eimeria spp. in all states of the Sudan.
\end{abstract}

Keywords: Prevalence; Eimeria Spp; Broiler Chickens; Open and Closed Systems; Sudan

\section{Introduction}

Coccidiosis is an intestinal parasitic disease that has the greatest economic impact on poultry production. The annual worldwide losses due to coccidiosis exceed two billion Euros for prophylaxis and medication [1]. Additional economic losses include mortality, morbidity, and poor feed conversion of birds that survive out breaks [2]. Eimeria, an intracellular protozoan parasite belongs to the Phylum Apicomplexa, is the causative agent of coccidiosis. Seven species of Eimeria are known to infect chickens. These are E. acervulina, E. brunetti, E. maxima, E. mitis, E. necatrix, E. praecox and E. tenella [3,2]. Prevalence and identification of Eimeria species are useful tools for prevention and control of coccidiosis [4]. The prevalence may vary from less than $10 \%$ to more than $90 \%$ in broilers worldwide $[5,6,7,4]$.

In the Sudan, five Eimeria species were identified during an outbreak of coccidiosis in a farm at Khartoum. These included E. tenella, E. maxima, E. mivati, E. parecox and E. brunette [8]. Reported by in a survey conducted in Khartoum State, Sudan that coccidiosis was widespread and three species were identified E. tenella, E. mivati and E. necatrix. Recently, E. tenella was isolated and identified in broiler chickens in Khartoum State Khaier, et al. 2015a $[9,10]$. In addition, E. acervulina was isolated and molecularly characterized in broiler chickens in the same State [11].Little information is available on infection rate of poultry coccidiosis in Khartoum State. The present study aimed to detect the prevalence of Eimeria spp. in broiler chickens in open and closed systems in the three cities of Khartoum State (Khartoum, Khartoum North, and Omdurman).

\section{Materials and Methods}

\section{Study Area}

The study was conducted in Khartoum State from October 2013 to February 2014 in some of the broiler farms. According to, two production systems are dominated in Khartoum; these are the closed and open systems [12]. The closed system production is adopted mainly by the intensive broiler production units of medium and large size. These units represented $10 \%$ of the broilers farm and produced $95.4 \%$ of the total broiler production [12]. The open system is accounted for about $90 \%$ of the broiler units in the State; it participated by less than $5 \%$ of the total production [12].

\section{Study Population}

The study population consisted of broiler chickens from Khartoum State comprising the three cities; Khartoum, Omdurman and Khartoum North.

\section{Sampling}

Six farms of different types, three open and three closed were randomly selected and visited once during October 2013 to February 2014 from each city. Five intact intestines from each farm were immediately collected after slaughtering of broilers either at slaughter house or farms. A total of 90 broiler intestines were collected and examined for the presence of Eimeria spp. The samples were labeled by writing the name of farm, date and address and brought in ice boxes to the Department of Parasitology, Faculty of Veterinary Medicine, University of Khartoum for examination and identification of coccidian oocysts.

\section{Parasitological Examination}

The intestine of slaughtered chickens was placed in a tray. Double ligature was applied to separate different parts of the intestine into: duodenum, jejunum, ileum and cecum. Each part of the intestines was opened by scissor, its contents were collected in a beaker. The contents of the intestines were examined for the presence of Eimeria spp. oocysts by direct smear and standard floatation method [13]. Eimeria spp. oocysts 
were purified and identified according to the site of infection, oocyst morphology including size and shape after sporulation and sporulation time [14].

\section{Statistical Analysis}

The SPSS computer program was used to analyze the data. Results were presented in the form of frequencies. Chi-square test was run to investigate association between farms location, type of production system and prevalence of Eimeria spp. Results were considered significant at $\mathrm{P} \leq$ 0.05 .

\section{Results}

A total of 90 broiler intestines were collected and examined for the presence of Eimeria spp. oocysts from poultry farms in Khartoum (30), Khartoum North (30) and Omdurman (30). The overall prevalence of Eimeria spp among broiler was $5.5 \%$. (5/90). Two Eimeria spp. were identified these were: Eimeria tenella in the cecum and Eimeria acervulina in the duodenum and jejunum. E. tenella showed the highest prevalence $5.5 \%$ followed by E. acervulina $2.2 \%$. The highest prevalence of Eimeria spp was in Khartoum City 10\% followed by Khartoum North City $6.7 \%$ and Omdurman City $0 \%$ (Table 1). No significant difference in infection rate with Eimeria spp. was found among the three cities of Khartoum State $(\mathrm{P}>0.05)$.

Table 1: Prevalence of Eimeria spp. in broiler chickens in the three cities of Khartoum State

\begin{tabular}{|c|c|c|c|}
\hline City & No Examined & No. +ve & \% +ve \\
\hline Khartoum & 30 & 3 & $10 \%$ \\
\hline Khartoum North & 30 & 2 & $6.70 \%$ \\
\hline Omdurman & 30 & 0 & $0 \%$ \\
\hline
\end{tabular}

Three out of 30 broiler intestines were found positive for E. tenella 10 $\%$ in Khartoum City (Table 1). In the closed system 3 out of 15 intestines were positive for E. tenella $20 \%$ with significant difference $(\mathrm{P} \leq 0.05)$ (Table 2). On the other hand, no parasites were found in 15 broilers in the open system (Table 2). In Khartoum North City, 6.7\% (2/30) intestines were infected with E. tenella and E. acervulina (Table 1). The prevalence of E. tenella and E. acervulina was $13.3 \%$ in the open system (Table 2). However no parasite was found in 15 broilers in the closed system (Table 2). No Eimeria spp. was detected in broiler intestines in Omdurman City in the both open and closed systems (Table 2). In Khartoum State, the overall prevalence of Eimeria spp. in the open and closed systems was 4.4 $\%(2 / 45)$ and $6.7 \%(3 / 45)$, respectively (Table 3$)$. Mixed infection with E. tenella and E. acervulina was detected in broilers of the open system, while the closed system chickens were infected only with E. tenella.

Table 2: Prevalence of Eimeria spp. in broiler chickens in open and closed systems in the three cities of Khartoum State

\begin{tabular}{|c|c|c|c|c|c|c|}
\hline \multirow{2}{*}{ City } & \multicolumn{3}{|c|}{ Closed system } & \multicolumn{3}{c|}{ Open system } \\
\cline { 2 - 7 } & $\begin{array}{c}\text { No. } \\
\text { examined }\end{array}$ & $\begin{array}{c}\text { No. } \\
\text { +ve }\end{array}$ & $\mathbf{\%}$ & $\begin{array}{c}\text { No. } \\
\text { examined }\end{array}$ & No. +ve & $\%$ \\
\hline Khartoum & 15 & 3 & 20 & 15 & 0 & 0 \\
\hline $\begin{array}{c}\text { Khartoum } \\
\text { North }\end{array}$ & 15 & 0 & 0 & 15 & 2 & 13.3 \\
\hline Omdurman & 15 & 0 & 0 & 15 & 0 & 0 \\
\hline Total & 45 & 3 & 6.7 & 45 & 2 & 4.4 \\
\hline
\end{tabular}

Table 3: Overall Prevalence of Eimeria spp. among broiler chickens in open and closed systems in Khartoum State

\begin{tabular}{|c|c|c|c|}
\hline \multirow{2}{*}{ System } & \multicolumn{2}{|c|}{ Eimeria spp. } & \multirow{2}{*}{ Prevalence (\%) } \\
\cline { 2 - 4 } & No. examined & No. +ve & 4.4 \\
\hline Open & 45 & 2 & 6.7 \\
\hline Closed & 45 & 3 & 5.5 \\
\hline Total & 90 & 5 & \\
\hline
\end{tabular}

\section{Discussion}

In the present study two Eimeria spp. were identified in naturally infected broiler chickens in Khartoum State. The species were E. tenella and E. acervulina. These results are in agreement with previously reported by except that E. necatrix was not detected [9]. These results suggesting that those species of Eimeria are widespread in most countries where poultry are produced on a commercial basis $[15,16,17,18]$.The overall prevalence of Eimeria spp. among broiler chickens in Khartoum State was $5.5 \%$, this rate is low compared with previous studies in other countries, in Ethiopia 20.6 \%, in Egypt 21.24 \%, in Zaria, Nigeria 33.3\% and $37.1 \%$, 78 \% in Jordan, 55.9 \% in Iran, 71.9 \% in Pakistan , 88.4 \% in Argentina and $92 \%$ in Romania $[15,16,19,20,21,22,23,24]$. The low prevalence of the Eimeria spp. reported in this study could be attributed only to that our study was conducted during the dry season (winter).

The current study showed that E. tenella was the dominant species (5.5\%) followed by E. acervulina (2.2\%). This in conformity with the findings of $[15,25,26]$. These authors reported that E. tenella is the most prevalent species in Africa, Middle East and Asia. However, disagrees with who reported E. acervulina was the most prevalent species in Iran as in Europe, Australia and North America [27]. The present study observed high prevalence of Eimeria spp. in the closed system $6.7 \%$ compared with the open system $4.4 \%$. This agrees with previous reports that coccidiosisis most common to bird under intensive management especially those on deep litter and this could be attributed to relatively higher oocyst accumulation in the deep litter and intensive rearing conditions $[28,29,30]$. Mixed infection with E. acervulina, E. tenella was observed in the open system in Khartoum North. The same findings were observed in China, in small-scale farms where more than one Eimeria species existed in most of the samples [31]. In conclusion the present study reported two Eimeria spp. viz E. tenella and E. acervulina in broiler chicks reared in open and closed systems in Khartoum State, Sudan. Further studies should be conducted to determine the prevalence of Eimeria spp. throughout the year in Khartoum State. Researchers are argued to achieve surveys in all States of Sudan to determine the prevalence of Eimeria spp. and to identify the present species.

\section{Acknowledgment}

The authors thank chicken farms' owners for allowance collecting the samples.

\section{Conflict of Interest}

The authors declare that no interest conflict.

\section{References}

1. Dalloul RA, Lillehoj HS. Poultry coccidiosis: recent advancements in control measures and vaccine development. Expert Review of Vaccines.2006;5:143-163.doi: 10.1586/14760584.5.1.143 
2. Williams R B. Epidemiological aspects of the use of live anticoccidial vaccines for chickens. International Journal for Parasitology.1998;28:1089-1098.

3. Shirley MW, Long PL. Control of coccidiosis in chickens: immunization with live vaccines. In Long PL, editor. Coccidiosis of Man and Domestic Animals. CRC Press, Boca Raton, Florida.1990:321-341.

4. Morris GM, Gasser RB. Biotechnological advances in the diagnosis of avian coccidiosis and the analysis of genetic variation in Eimeria. Biotechnology Advances.2006;24(6):590-603.

5. Lee BH, Kim WH, Jeong J, Yoo J, Kwon YK, Jung BY, et al. Prevalence and crossimmunity of Eimeria species on Korean chicken farms. Journal of Veterinary Medical Science.2010;8:985-989.

6. Haug A, Gjevre A, Thebo P, Mattsson JG, Kaldhusdal M. Coccidial infections in commercial broilers: Epidemiological aspects and comparison of Eimeria species identification by morphometric and polymerase chain reaction techniques. Avian Pathology.2008;37:161-170. doi:10.1080/03079450801915130

7. Karaer Z, Guven E, Akcay A, Kar S, Nalbantoglu S, Cakmak A. Prevalence of subclinical coccidiosis in broiler farms in Turkey. Tropical Animal Health and Production.2012;44:589-594.

8. Mohammed A, Osman AY, Gasmir GS, Aziz AA. Multiple infection with Eimeria spp. in chicken in Khartoum Province. Sudan journal of Veterinary Science and Animal Husbandry.1990;29:31-38.

9. Ali SF, Abdalla HS, Osman AY, Salim AI. Survey of Eimeria species in poultry in Khartoum Province. The Sudan Journal of Veterinary Research.1991;10: 44-45.

10. Khaier MAM, Abdelhalim AI, Abukashawa SMA. Isolation and morphological identification of Eimeria tenella (Family: Eimeriidae) from Khartoum State, Sudan. Journal of Applied and Industrial Sciences.2015a;3(5):177-181.

11. Khaier MAM, Salih MA, Abukashawa SMA. Molecular characterization of Eimeria acervulina in broiler chickens. Curr. Res. Microbiol. Biotechnol.2015b;3(1):569-572.

12. Anon. Ministry of Agriculture, Animal Resources and Irrigation. Khartoum State. 2009;80-81.

13 Soulsby EJ. Helminths, Arthropods and Protozoa of Domesticated Animals, 7th ed.: Bailliere Tindall;London. 1982;630-639.

14. Anon. Manual of Veterinary Parasitological Laboratory Techniques. Ministry of Agriculture, Fisheries and Food (MAFF).. Her Majesty's Stationary Office, London.1984; Reference Book 418:11-12.

15. Al-Natour MQ Suleiman MM, Abo-Shehadab MN. Flock-level prevalence of Eimeria species among broiler chicks in Northern Jordan. Preventive Veterinary Medicine.2002;53:305-310.

16. McDougald LF, Mattiello RA. Survey of coccidia on 43 poultry farms in Argentina. Avian Disease.1997;41(4):923-929.
17.Thebo P, Uggla A, Hooshmand-Rad P. Identification of seven Eimeria species in Swedish domestic fowl. Avian Pathology.1988;27:613z617.

18. Williams RB, Bushell AC, Reperant JM, Doy TG, Morgan JH, Shirley MW, et al. A survey of Eimeria species in commercially reared chickens in France during 1994. Avian Pathology.1996;25:113-130.

19. Gari G, Tilahun G, Dorchies P. Study on poultry coccidiosis in Tiyo District, Arsi Zone, Ethiopia. International Journal of Poultry Science. 2008;7(3):251-256.

20. Ahmed AA, Olfat AM, Aida ANE, Mohamed SA. Studies on coccidia of Egyptian Balady breed chickens. Life Science Journal. 2012;3:568-576.

21. Jatau ID, Sulaiman NH, Musa IW, Lawal AI, OkubanjoIsah 00, Magaji Y. Prevalence of coccidia infection and preponderance Eimeria species in free range indigenous and intensively managed exotic chickens during hot-wet season, in Zaria, Nigeria. Asian Journal of Poultry Science.2012;6:79-88.

22.Nematollahi A, Moghaddam GH, Pourabad RF. Prevalence of Eimeria species among broiler chicks in Tabriz, Northwestern of Iran. Munis Entomology Zoology. 2009;4:5358.

23. Khan M Q, Irshad H, Anjum R, Jahangir M, Nasir U. Eimeriosis in poultry of Rawalpindi/ Islamabad area. Pakistan Veterinary journal.2006;26:85-87.

24.Gyorke A, Pop L, Cozma V. Prevalence and distribution of Eimeria species in broiler chicken farms of different capacities. Parasite.2013;20:50. doi: 10.1051/ parasite/2013052

25. Al-Quraishy S, Abdel-Baki A, Dkhil M. Eimeria tenella infection among broiler chicks Gallus domesticus in Riyadh City, Saudi Arabia. Journal of King Saud UniversityScience.2009;21(3):191-193.

26. Awais MM, Akhtar M, Iqbal Z, Muhammad F, Anwar MI. Seasonal prevalence of coccidiosis in industrial broiler chickens in Faisalabad Punjab Pakistan. Tropical Animal Health and Production.2012;44(2):323-328. doi: 10.1007/s11250-011-0024-x. Epub 2011 Nov 20

27. Shirzad MR, Seifi S, Gheisari HR, Hachesoo BA, Habibi H, Bujmehrani H. Prevalence and risk factors for subclinical coccidiosis in broiler chicken farms in Mazandaran province Iran. Tropical Animal Health and Production.2011;43(8):1601-1604.

28.Methusela S. Studies on Prevalence and Economic Impacts of Poultry Coccidiosis in Different Production Systems in DebreZeit and Addis Ababa Ethiopia. M.Sc thesis. Faculty of Veterinary Medicine, Free University of Berlin, DebreZeit, Berlin.2001.

29.Taylor MA, Coop RL, Wall RL. Parasite of Poultry and Game Bird. In: Anderson JM, Macfadyen A, editors. Veterinary Parasitology, Iowa State: Blackwell Publishing. USA.2007:459-557.

30.Williams R.B. Epidemiological studies of coccidiosis in the domestic fowl (Gallus gallus). II. Physical condition and survival of Eimeria acervulina oocysts in poultry house litter. Applied Parasitology.1995;36:90-96.

31. Sun XM, Pang M, Jia T, Yan WC, He G, Hao LL, et al. Prevalence of Eimeria species in broilers with subclinical signs from fifty farms. Avian Diseases.2009;53(2):301-305. 